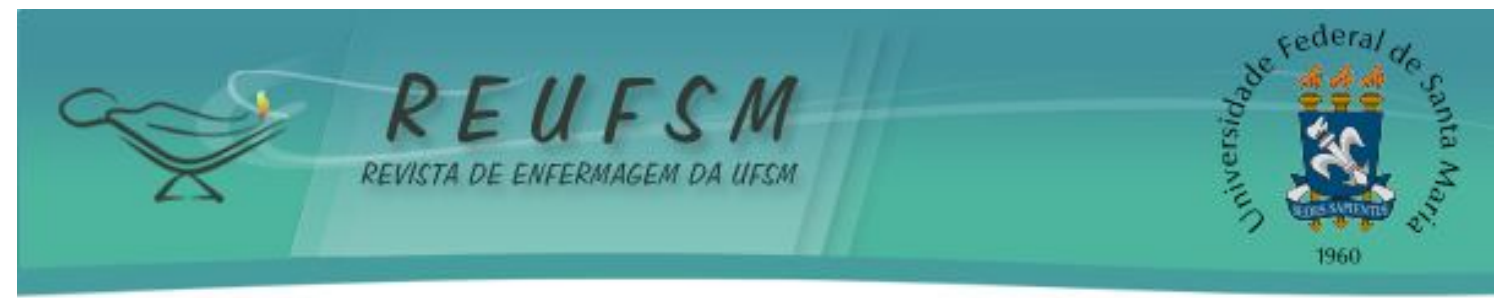

RELATO DE EXPERIÊNCIA

\title{
CUIDADOS DE ENFERMAGEM A CLIENTE SUBMETIDO À FASCIOTOMIA - RELATO DE EXPERIÊNCIA
}

\section{NURSING CARE TO CLIENT SUBMITTED TO FASCIOTOMY - EXPERIE NCE REPORT CUIDADOS DE ENFERMERÍA A CLIENTE SOMETIDO A FASCIOTOMÍA- INFORME DE EXPERIENCIA}

Rodrigo Marques da Silva ${ }^{1}$ Rhea Silvia de Avila Soares ${ }^{2}$

Laura de Azevedo Guido ${ }^{3}$

RESUMO: Este estudo descreve a assistência de enfermagem e as coberturas e produtos utilizados em um paciente submetido à fasciotomia e sua evolução. Trata-se de um relato de experiência realizado de Março à Maio de 2010. Realizou-se a higienização com Prontosan e utilizou-se gaze vaselinada para manutenção da umidade ideal para cicatrização. No 5o pós-operatório, substituiu-se a gaze vaselinada pelo Alginato de Cálcio devido ao grande volume de exsudato. Vinte dias depois, trocou-se o Alginato pela gaze vaselinada, associada à Colagenase ou Hidrogel, devido à redução da exsudação. Mantevese a conduta até reduzir o edema muscular e controlar a infecção para enxertia. Então, utilizou-se gaze vaselinada e PVPI Tópico na área doadora e gaze vaselinada e Triglicerídeos de Cadeia Média nas receptoras. Conluiu-se que enfermeiro é responsável pela indicação do tratamento dispensado e que a padronização das condutas e seus registros permitem a assistência contínua e a avaliação do cuidado prestado.

Descritores: Estudantes de enfermagem; Enfermagem; Cicatrização de feridas.

ABSTRACT: This study describes the nursing care and coverage and products used in a patient who underwent fasciotomy and its evolution. This is an experience report conducted from March to May 2010. The cleaning was made with Prontosan and vaseline gauze was used to maintain to healing humidity ideal. On the 5th postoperative day, replaced the vaseline gauze by calcium al ginate due to the large volume exudate. Twenty days later, switched to the alginate by vaseline gauze, hydrogel or associated with Collagenase, due to reduction of exudation. Remained the conduct even reduce the muscle swelling and infection control for grafting. Then, we used vaseline gauze and topic PVPI in the donor area and vaseline gauze and Medium Chain Triglycerides in the recipient. Has concluded that nurses are responsible for the appointment of the treatment given and that the standardization of conduits and their records provide continued assistance and provided care evaluation.

Descriptors: Students, nursing; Nursing; wound healing.

RESUMEN: Este estudio describe los cuidados de enfermería, coberturas y productos utilizados en un paciente que sufrió fasciotomía y su evolución. Este es un relato de experiencia realizado

\footnotetext{
${ }^{1}$ Acadêmico do Curso de Enfermagem. Bolsista PIBIC (CNPQ). Universidade Federal de Santa Maria. E-mail: marques-sm@hotmail.com

2 Enfermeira do Hospital Universitário de Santa Maria (HUSM), Unidade de Clinica Cirúrgica, Especialista em Saúde Pública pela Faculdade Internacional de Curitiba, Coordenadora do Grupo de Estudos de Lesões de Pele (GELP) do HUSM.

${ }^{3}$ Enfermeira. Profa Adjunta do Departamento de Enfermagem da Universidade Federal de Santa Maria. Coordenadora do Programa de Pós-graduação em Enfermagem da UFSM. Líder do Grupo de Pesquisa Trabalho, Saúde, Educação e Enfermagem, Linha de Pesquisa Stress, Coping e Burnout. E- mail: Iguido344@gmail.com
} 


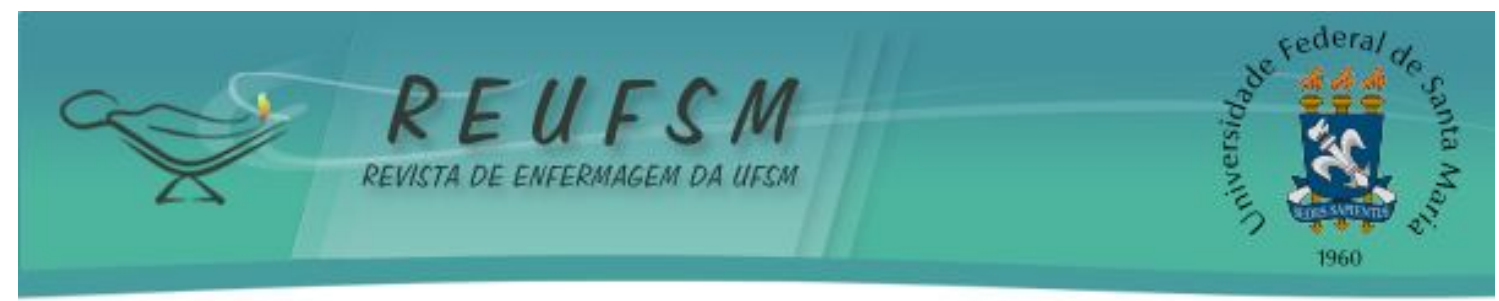

entre Marzo y Mayo de 2010. Se utilizó Prontosan para la limpieza y gasa vaselinada para mantener la humedad ideal para la cicatrización. En el 5o postoperatorio, fue reemplazada la gasa por el alginato de calcio debido a la gran cantidad de exudado. Veinte días después, se cambió el Alginato por la gasa, con hidrogel o colagenasa asociados, porque la exudación disminuyó. Se mantuvo la conducta hasta reducir el edema muscular y control de infección para el injerto. Entonces, se utilizó gasa vaselinada y PVPI en la zona donante y gasa vaselinada y triglicéridos de cadena media en las receptoras. Se concluyó que las enfermeras son responsables por designar el tratamiento y qué la estandarización de enfoques y sus registros permiten asistencia continua y la evaluación del cuidado.

Descriptores: enfermería; estudiantes de enfermería; Cicatrización de Heridas.

\section{INTRODUÇÃO}

No decorrer da história, verifica-se a multiplicidade de conhecimentos adquiridos pelo homem nos distintos campos do saber. Ao observar o passado é possível compreender a evolução do conhecimento técnico-científico numa época em que emerge a globalização, com abertura para o mercado internacional. ${ }^{1}$

Assim, desde os tempos rudimentares, novas formas de prevenção e tratamento a patologias têm sido produzidas, o que demanda adequação e renovação das atividades pertinentes ao exercício profissional do enfermeiro. Assistir ao paciente, em número e qualidade, de acordo com a sua complexidade, para satisfazer à instituição de saúde, aos pacientes e aos próprios trabalhadores, é meta dos enfermeiros. ${ }^{1,2}$

No que se refere aos tratamentos de pacientes portadores de lesões de pele, desde a antiguidade até o período atual, encontra-se uma indústria diversificada de produtos, coberturas e instrumentos cada vez mais eficazes para a prevenção e tratamento de feridas.

No Brasil, as lesões de pele constituem um problema de saúde pública devido ao número elevado de doentes com alterações na integridade da pele, embora sejam escassos os registros desses atendimentos. 0 número de pessoas portadoras de feridas contribui para onerar o gasto público, nem sempre com a resolutividade esperada. ${ }^{3}$

A prática de cuidados a pacientes com feridas é uma especialidade na enfermagem, reconhecida pela Sociedade Brasileira de Enfermagem Dermatológica (SOBEND) e Associação Brasileira de Estomaterapia (SOBEST). Além disso, é uma atividade que requer conhecimento específico, habilidade e abordagem integral. ${ }^{4}$ Assim, o cuidado a esses pacientes é um desafio a ser enfrentado pela equipe, em especial pelo enfermeiro, por ser um fator que influencia na qualidade de vida das pessoas. ${ }^{4,5}$

Por isso, no desenvolvimento das atividades de enfermagem, é importante que o enfermeiro avalie as feridas e indique os produtos e coberturas adequadas para cada situação a fim de obter a melhor evolução possível ao paciente. ${ }^{6}$ Ao realizar tal avaliação, é importante não haver restrição do tratamento ao uso de produtos e coberturas, deve-se levar em consideração os fatores locais, como a etiologia da ferida, e gerais, a exemplo do estado nutricional, envolvidos na cicatrização.

Sobre isso, destaca-se que os pacientes com lesões de pele têm maior necessidade de proteínas, energia e micronutrientes, devido às perdas pelo exsudato da ferida, à necessidade de matéria-prima para a formação de novos tecidos e à redução da ingestão alimentar. ${ }^{4}$ Logo, evidencia-se que a nutrição adequada tem um papel importante na cicatrização e é de responsabilidade do enfermeiro avaliá-la em conjunto com o nutricionista, visto a importância do trabalho multiprofissional dispensado ao cliente. ${ }^{4}$

Além da nutrição, outros fatores como a fragilidade vascular, o turgor cutâneo, a mobilidade e a idade, também interferem na cicatrização. Entretanto, a etiologia da ferida, que 


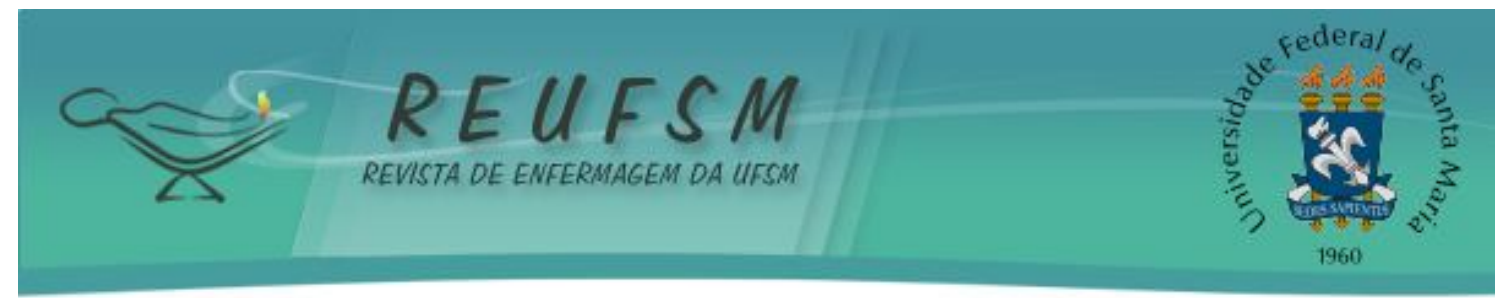

pode ser cirúrgica, traumática e (ou) crônica, é determinante para a indicação do tratamento a ser dispensado, pois os cuidados e orientações ao paciente são específicos para cada tipo de lesão. ${ }^{7}$

Aquelas de origem traumática são observadas com freqüência em unidades de internação cirúrgica devido a acidentes automobilísticos e motociclísticos. Esses causam lesões de alto impacto nos membros superiores e inferiores e a fasciotomia descompressiva é, na maioria das vezes, a conduta de rotina. Esse é um procedimento cirúrgico que consiste na realização de uma incisão na fáscia muscular para aliviar a pressão (e tratar a perda de circulação em uma área de tecido ou músculo). ${ }^{8}$

Além disso, a fasciotomia evita a instalação da síndrome compartimental (caracterizada por edema, enrijecimento da região acometida, parestesia, dor contínua e hipoestesia) que pode evoluir para a contratura isquêmica de grupos musculares, conhecida como síndrome de Volkmann. Tal síndrome ocorre quando há elevada pressão dentro de um espaço músculo-ósteo-aponeurótico fechado, o que reduz a perfusão capilar a níveis abaixo do necessário para manter a viabilidade tecidual. Sua incidência é maior na perna e antebraço, com etiologia variável. O diagnóstico imediato e a descompressão por fasciotomia são essenciais para a preservação da função, do membro e, eventualmente, da vida. ${ }^{8}$

Dessa forma, com vista às freqüentes lesões de pele que necessitam a realização de fasciotomia e à necessidade de cuidados de enfermagem eficazes no tratamento prestado, faz-se necessário verificar como têm sido realizados estes cuidados e se os pacientes têm atingido os resultados esperados. Objetiva-se descrever condutas na assistência de enfermagem, as coberturas e os produtos utilizados pelos enfermeiros em um paciente, submetido à fasciotomia, internado na Unidade de Clínica Cirúrgica (UCC) do Hospital Universitário de Santa Maria (HUSM) e sua respectiva evolução durante o período de internação. A partir disso, busca-se avaliar as condutas e descrever os curativos realizados pel os enfermeiros desta unidade.

\section{MÉTODO}

Trata-se de um relato de experiência realizado entre os meses de Março à Maio de 2010 na UCC do HUSM por um estudante de enfermagem em atividades práticas por meio do PROFCEN (Programa de Formação Complementar em Enfermagem). Esse é um Programa de Ensino e Extensão elaborado pela coordenação do Curso de Enfermagem da Universidade Federal de Santa Maria (UFSM) que oportuniza vivências aos acadêmicos de enfermagem para desenvolver competências e habilidades técnico-científicas, éticopolíticas e sócio-educativas do profissional enfermeiro. No decorrer dessas vivências realizaram-se atividades de competência do enfermeiro. Dentre elas os cuidados aos pacientes com lesões de pele. Neste estudo, abordaram-se as condutas de enfermagem referentes a um dos pacientes acompanhados, que foi submetido a uma fasciotomia descompressiva após trauma muscular causado por acidente automobilístico.

Uma parte dos docentes e dos enfermeiros que atua na área de prevenção e tratamento de feridas apresenta a preocupação de ensinar os seus alunos a prestarem uma assistência individualizada, sistematizada, pautada na avaliação e indicação da cobertura ideal para a cicatrização da lesão que se cuida. ${ }^{9}$ Logo, o PROFCEN possibilita ao aluno ampliar sua prática relativa a este cuidado, pois realizar curativo é uma tarefa não automatizada e sim reflexiva; necessita de um conhecimento teórico relacionado à fisiologia da pele, dos produtos existentes no mercado e daqueles que são padronizados pelo hospital.

Como esse estudo trata-se de um relato de experiência da prática de enfermagem em uma unidade hospitalar, considerou-se desnecessário o encaminhamento de um projeto para o Comitê de Ética e Pesquisa. Contudo, obteve-se o consentimento formal do paciente, mediante assinatura do Termo de Consentimento Livre e Esclarecido, para publicação do estudo e divulgação das imagens do seu tratamento. 


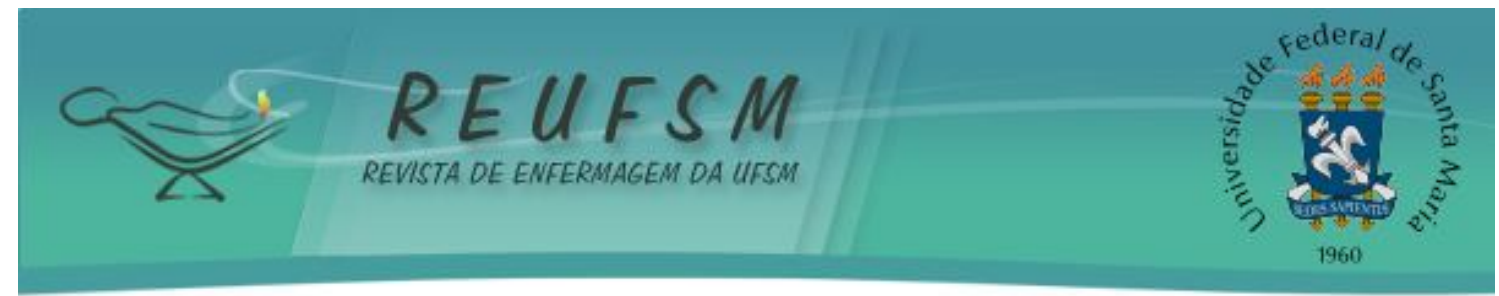

RESULTADOS E DISCUSSÃO

JCR, 35 anos de idade internou no Pronto Socorro do HUSM, no dia 1o de março de 2010, politraumatizado após acidente automobilístico. Apresentava fratura de ulna direita com foco de exposição externa, fratura de fêmur direito, fratura de tíbia esquerda, com baixa perfusão de membro inferior direito. Ele foi encaminhado ao Bloco cirúrgico onde foi realizada redução da fratura do fêmur direito com instalação de fixador externo no local, colocação de tala gessada em antebraço direito e em tíbia esquerda. Além disso, necessitou a realização de um Bypass em lesão de artéria femoral superficial a partir de artéria poplítea direita e uma fasciotomia medial e lateral de perna direita. Dessa forma, a ferida originária da fasciotomia permaneceu com as bordas afastadas para facilitar a redução do edema (Síndrome Compartimental) e conseqüente descompressão do local afetado. Logo, foi necessária a avaliação da lesão e a realização de curativos pelas enfermeiras da unidade, durante o período de internação, ou seja, do dia 10 de março até a alta hospitalar no dia 24 de maio de 2010.

Destaca-se que o estudante envolvido realizou as avaliações e os curativos junto à enfermeira da Unidade no turno da manhã, período em que realizava as atividades do PROFCEN. Dessa forma, realizou-se ensino e assistência de maneira articulada, o que contribuiu para o aprendizado do referido acadêmico, bem como para o exercício da atividade de pesquisa, com suporte do professor orientador.

Tem-se como rotina, nesta instituição, a realização de curativos nos três turnos (manhã, tarde e noite), com freqüência dependente do quadro clínico do paciente e das características da lesão. Com base nisso, a enfermeira indica os produtos a serem utilizados como coberturas. Posteriormente, os curativos subseqüentes são avaliados, realizados e registrados e, conforme a evolução do processo cicatricial. Os mesmos produtos são mantidos em uso pelas enfermeiras dos outros turnos. A conduta é alterada quando, após avaliação, a enfermeira de algum dos turnos julga necessário.

Para este estudo, realizaram-se os curativos no turno da manhã no referido paciente, avaliou-se a ferida da fasciotomia e utilizaram-se as coberturas indicadas pela enfermeira responsável. Além disso, verificaram-se os registros dos curativos desse paciente realizados pela equipe de enfermagem do hospital.

Os produtos utilizados durante o tratamento foram: Prontosan, Gaze Vaselinada, Alginato de Cálcio, Colagenase, Hidrogel, PVPI (Polivinil Pirrolidona- lodo), TCM (Triglicerídeos de Cadeia Média). Eles foram utilizados na ferida conforme suas características ao longo do processo cicatricial.

Inicialmente, as feridas produzidas pela fasciotomia apresentavam tecido de granulação vermelho- vivo, o que o configura como saudável, e edema no tecido muscular (Figura 1). Dessa forma, nos primeiros cinco dias de internação, a enfermeira do turno da manhã indicou a higienização da mesma com Prontosan (Solução) e a utilização de gaze vaselinada em seu leito (Figura 2). A solução consiste em um produto para limpeza e é indicado para hidratar a ferida e acelerar a cicatrização. Além disso, pode ser usada em área de necrose de liquefação, pois possui função desbridante. 0 que é confirmado em um estudo $^{10}$ com 10 pacientes, tratados com Prontosan, que demonstrou ser este uma alternativa adequada para a limpeza, umidificação e remoção de necroses. A gaze vaselinada auxilia na hidratação do leito da ferida, mantém um meio ideal para a cicatrização, evita lesões no tecido de granulação e é indicada para lesões superficiais de queimaduras, úlceras, áreas doadoras e receptoras de enxerto, abrasões, lacerações e demais lesões com necessidade da não-aderência do curativo à lesão. ${ }^{7,11}$ 


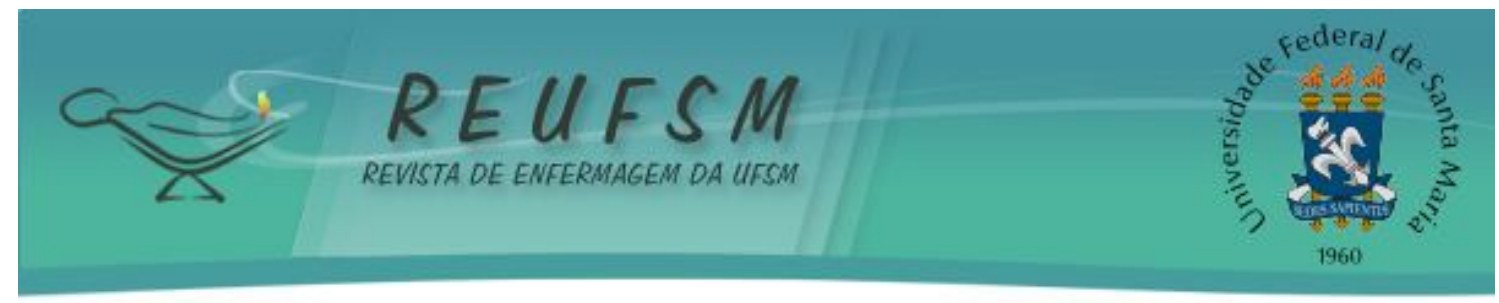

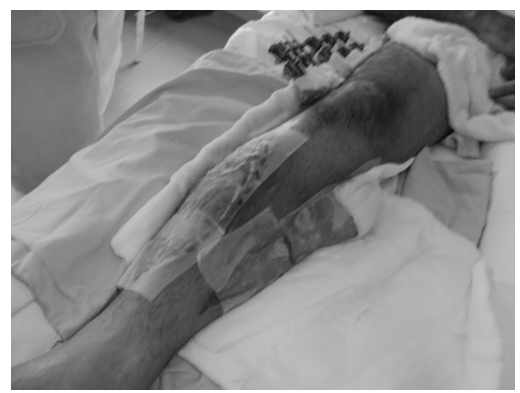

Figura 1- Situação inicial da lesão

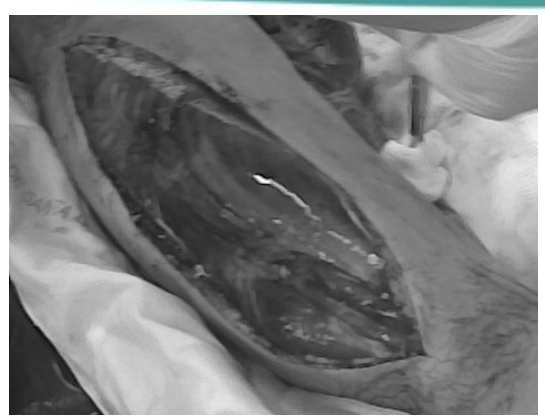

Figura 2 - Uso de gaze vaselinada e prontosan

Após os primeiros cinco dias de pós-operatório (5PO), as feridas apresentavam-se com tecido de granulação vermelho-vivo, áreas de necrose de liquefação e eliminação de grande volume de exsudato seroso. Tal exsudato é comum na fase inflamatória da lesão e também ocorre devido à presença de tecidos necróticos que estimulam uma reação inflamatória exacerbada. ${ }^{11}$

Dessa maneira, foi mantida a higienização da ferida com Prontosan e, devido ao grande volume de exsudato seroso na ferida e dor intensa que o paciente relatou, substituiu-se a gaze vaselinada pelo Alginato de Cálcio. Tomou-se essa conduta porque o Alginato de Cálcio tem alta capacidade absortiva, impede a maceração das bordas da lesão em casos de grandes volumes de exsudato drenados e possibilita a troca somente do curativo externo. Isso reduz custos e também a agressão causada pelo próprio curativo ao tecido, além de não expor o paciente a dor. ${ }^{7,11}$

Passados 20 dias do uso de Alginato nas lesões (250 PO), houve redução do edema muscular e do volume de secreção drenada, além da diminuição da área necrótica. Assim, manteve-se a prescrição de higienização do leito da ferida com Prontosan e trocou-se o Alginato pela gaze vaselinada novamente devido à redução do exsudato drenado. Entretanto, desta vez, associou-se o uso da gaze vaselinada com Colagenase ou Hidrogel nas áreas de tecido desvitalizado restantes (Figura 3).

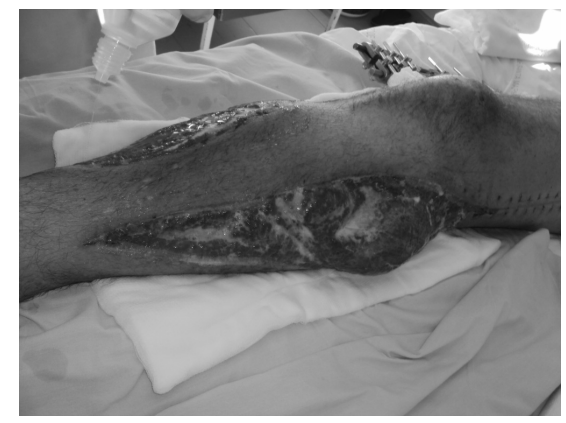

Figura 3 - Uso de gaze vaselinada associada ao hidrogel.

Esses dois últimos produtos são desbridantes enzimáticos e autolíticos respectivamente, que auxiliam na degradação de tecidos mortos presentes na ferida. Tais tecidos dificultam o processo cicatricial normal, intensificam a inflamação típica das feridas e produzem um volume grande de exsudato. ${ }^{6,11}$ Essa conduta foi mantida até redução total do edema dos músculos e controle da infecção (observado pela redução e posterior ausência de secreção seropurulenta), para então o paciente receber enxerto sobre as fasciotomias. No início do mês de maio, o paciente estudado realizou uma enxertia. A área doadora foi retirada da perna esquerda ao nível da coxa 


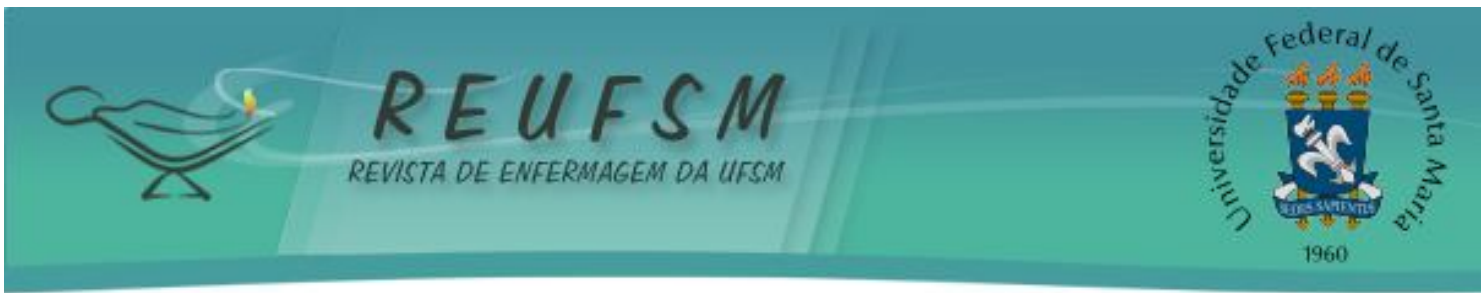

e utilizaram-se como coberturas, na área doadora, gaze vaselinada e PVPI Tópico (Figura 4), que é um produto com efeito antimicrobiano contra a maioria das bactérias gram-positivas e gram-negativas, fungos e vírus. Ele tem sua efetividade clínica comprometida, pois é inativado pelo exsudato da ferida e citotóxico aos fibroblastos. Entretanto, este fato não influenciou seu uso, pois a lesão não continha exsudato nesse momento do estudo. ${ }^{11} \mathrm{~A}$ gaze foi mantida na área doadora, irrigada com PVPI Tópico e recortada paulatinamente durante a realização dos curativos ao longo dos dias.

Nas áreas receptoras, que se apresentavam com bom aspecto cicatricial, foi utilizado gaze vaselinada e Triglicerídeo de Cadeia Média, que é um produto que mantém o leito da ferida com a umidade ideal para a granulação do tecido (Figura 5). No Brasil, o tratamento de úlceras por pressão e feridas com ácidos graxos essenciais de cadeia média e triglicerídeos (AGE-TG) foi popularizado após a publicação de Declair (1994), que observou alguns efeitos clínicos dos AGE-TG na prevenção de úlceras de decúbito. ${ }^{12}$

Além disso, vale destacar que o paciente JCR apresentava dieta livre e se alimentava bem. Isso também contribuiu para a boa evolução das lesões em questão, visto que as necessidades metabólicas, em pacientes que apresentam lesões de pele, são aumentadas e precisam ser supridas pela dieta.

Evidencia-se que cabe ao enfermeiro, como educador, auxiliar na instrumentalização técnico-científica do aluno de enfermagem para o desenvolvimento de suas habilidades. ${ }^{13}$ Por isso, a vivência é um momento de suma importância no processo de formação profissional e pessoal desse aluno, visto que o enfermeiro tem influência no desenvolvimento de habilidade, técnica e atitudes do estudante. ${ }^{14}$

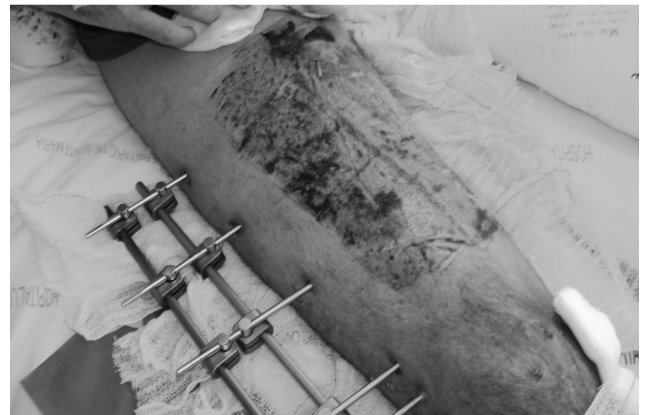

Figura 4 - Área doadora (gaze vaselinada e PVPI).

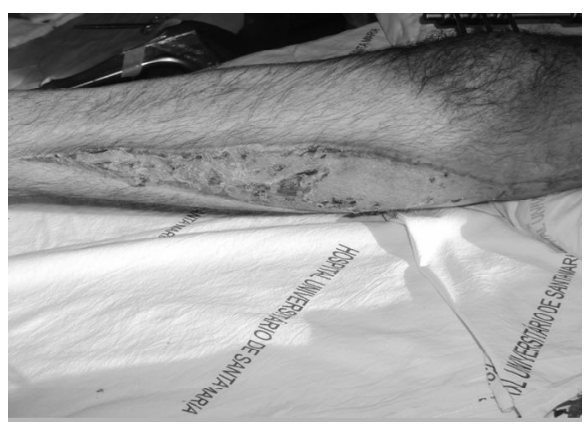

Figura 5 - Área receptora do enxerto.

\section{CONCLUSÃO}

O enfermeiro, enquanto profissional de saúde e responsável pelos cuidados ao portador de feridas, deve ter conhecimento para avaliar as lesões e estabelecer os produtos necessários a fim de garantir um tratamento eficaz e boa evolução. Não obstante, é importante considerar outros fatores envolvidos no processo de cicatrização, como a idade, a dieta, a fragilidade vascular e alteração da mobilidade e também fatores subj etivos, como o estado emocional do indivíduo com lesões de pele e o grau de aceitação e entendimento de sua condição. É preciso que haja uma padronização da conduta da equipe de enfermagem entre os turnos de atendimento, no que diz respeito à assistência e 


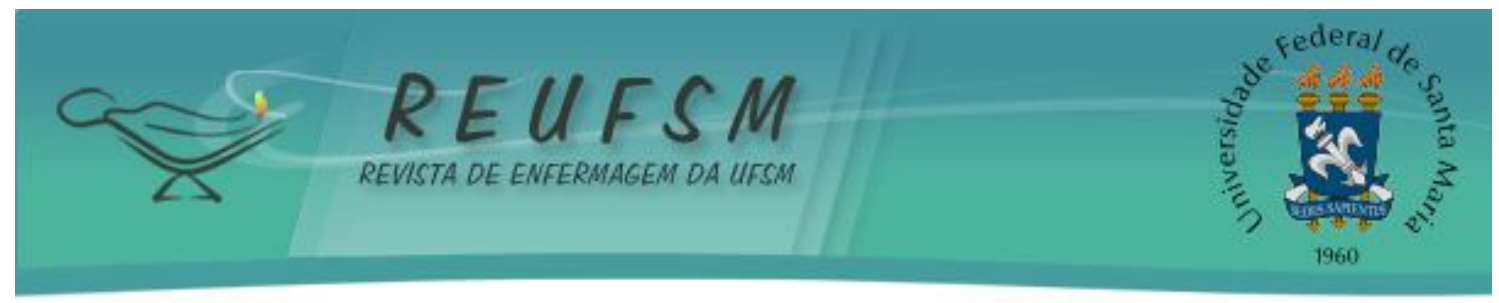

aos registros da mesma para propiciar uma assistência contínua e a possibilidade de avaliar o cuidado prestado, tanto pelos enfermeiros da unidade, quanto por estudos como esse.

Somado a isso, destaca-se que este trabalho possibilitou a ampliação do conhecimento do envolvidos em relação ao tema abordado e a interação com a equipe de enfermagem da Unidade de Clínica Cirúrgica. Ao estudante de enfermagem envolvido, destaca-se a realização do exercício da assistência, pesquisa e ensino de forma articulada e indissociável, em que a pesquisa surgiu da demanda assistencial e, não obstante, permitiu o aprendizado do mesmo.

Atualmente, há interesse entre os enfermeiros em ampliar e divulgar seus conhecimentos na área do tratamento de feridas. Dado que este é um importante cuidado de enfermagem, almeja-se que o tratamento de lesões de pele seja visto como uma especialidade que a cada dia mais exige conhecimento e resolutividade na atuação. Portanto, a divul gação deste estudo colabora neste sentido.

\section{REFERÊNCIAS}

1. Silva RM, Soares RSA, Cherobini MDB, Timm AMB. GELP: Grupo de estudos em lesões de pele do Hospital Universitário De Santa Maria- um relato de experiência. In: Anais do I Congresso de Iniciação Científica e Pós-Graduação; 2010 Set.13-16; Santa Catarina. Santa Catarina: Universidade do Estado de Santa Catarina; 2010, s. p.

2. Zimmermann LP, Magnago TSBS, Urbanetto J S, Greco PBT, Viero NC, Vieira TG et al. Avaliação do grau de dependência de cuidados de enfermagem dos pacientes internados em pronto-socorro. R Enferm UFSM. 2011; 1(2): 153-163.

3. Brasil. Ministério da Saúde (BR). Manual de condutas para úlceras neurotróficas e traumáticas. Brasília (DF); Ministério da Saúde; 2002.

4. Prazeres SJ , organizadora. Tratamento de feridas: teoria e prática. 1a ed. Porto Alegre: Moriá; 2009.

5. Santos AAR, Medeiros ABA, Soares MJ GO, Costa MML. Observação da técnica de curativo realizada pelos profissionais de enfermagem em um hospital público. Rev enferm UFPE on line [periódico na internet] 2010 jul-set [acesso em 2010 out 6]; (3):17-24. Disponível em: http:/ / www. ufpe. br/ revistaenfermagem/ index. php/ revista/ article/ view/ 928.

6. Silva RM, Soares RSA, Tavares JP, Ribeiro DB, Peres RR, Wilhelm LA. Coberturas utilizadas em pacientes no HUSM e sua eficácia no tratamento de feridas. In: Anais da Semana de Enfermagem Hospital Universitário de Santa Maria; 2010 Abr. 12-16; Santa Maria. Santa Maria: Hospital Universitário de Santa Maria; 2010, p. 56.

7. Lima IC, Santos JD, Marins RP, Ribeiro TM. Caderno de enfermagem em ortopedia. Curativos- Orientações Básicas. Ministério da Saúde. Secretaria de Assistência a Saúde. Instituto Nacional de Tráumato- Ortopedia, 2006, p. 32

Ministério da Saúde. Secretaria de Assistência à Saúde. Instituto Nacional de Traumato-

Ortopedia. Caderno de Enfermagem em Ortopedia. Curativos- Orientações Básicas.

Brasília; 2006 [citado em: 3 jul. 2010]. Disponível em:

http:/ / bvsms. saude.gov. br/ bvs/ publicacoes/ caderno_enfermagem_ortopedia.pdf.

8. Filho J MC. Síndrome de compressäo dos compartimentos osteofasciais e seu tratamento: a fasciotomia. Rev angiol cir vasc. 1993; 2(2):56-67.

9. Salomé GM, Espósito VHC. Vivências de acadêmicos de enfermagem durante o cuidado prestado às pessoas com feridas. Rev bras enferm. 2008; 61(6): 822-27. 


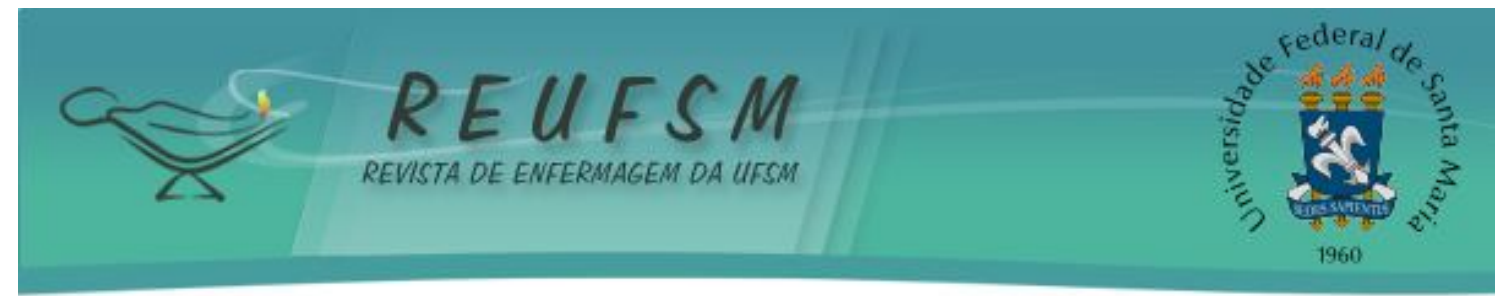

10. Horrocks A. Prontosan wound irrigation and gel: management of chronic wounds. $\mathrm{Br}$ J Nurs[acesso em 2010 Set 6];(22): 1224-8. Disponível em: http:/ / www. internurse. com/ cgibin/ go. pl/ library/ article. cgi ?uid=22559; article=BJ N_15_22 _ 1222_1228.

11. J orge AS, Dantas SRPE. Abordagem Multiprofissional do Tratamento de Feridas. São Paulo: Atheneu; 2008.

12. Cavazana WC, Simões MLPB, Yoshii SOA, Amado CAB, Cuman RKN. Açúcar (sacarose) e triglicerídeos de cadeia média com ácidos graxos essenciais no tratamento de feridas cutâneas: estudo experimental em ratos. An Bras Dermatol. 2009;84(3):229-36.

13. Esperidião E, Munari DB. Holismo só na teoria: a trama de sentimentos do acadêmico de enfermagem sobre sua formação. Rev Esc Enferm USP. 2004;38(3):332-40.

14. Ito EE, Takahashi RT. O estágio curricular da graduação de enfermagem em sua unidade de trabalho. Rev Esc Enferm USP. 2005; 39(1): 109-10.

Data de recebimento: 02/06/2011

Data de aceite: $22 / 07 / 2011$

Contato com autor responsável: Rodrigo Marques da Silva.

Endereço: Rua Conde de Porto Alegre, 1240. Apto 203. Bairro Centro. Santa Maria, RS.

CEP 97015110

E-mail: marques-sm@hotmail.com 